\title{
Primary Epiploic Appendagitis
}

\author{
Hugo Matos • Isidoro Costa
}

Received: 2 December 2013 / Accepted: 12 January 2014 / Published online: 21 January 2014

(C) Association of Surgeons of India 2014

\begin{abstract}
Primary epiploic appendagitis is an inflammation of the epiploic appendages occurring due to ischemic infarction as a result of appendage torsion or spontaneous thrombosis usually affecting patients from second to fifth decades, being more common in women and obese patients. It is a self-limiting entity with clinical features similar to other inflammatory abdominal processes and sometimes not remembered at clinical examinations. The awareness of this entity and its correct identification on imaging examinations could prevent unnecessary surgery. The authors present a clinical case complemented with ultrasound and CT images of this entity.
\end{abstract}

Keywords Epiploic appendages · Appendagitis .

Ultrasound $\cdot \mathrm{CT}$

A 30-year-old male patient presents with acute abdominal pain and localized tenderness over the lower left quadrant. No other signs or symptoms were present. Blood workup was normal.

An abdominal ultrasound was performed presenting an illdefined hyperechoic oval mass at the site of maximum tenderness, superficial to the sigmoid bowel wall, surrounded by a hypoechoic halo. The diagnosis of epiploic appendagitis was purposed, and CT confirmed a pericolic ovoid lesion, with fat density, surrounded by a hyperdense rim and inflammatory changes.

Primary epiploic appendagitis is an inflammation of the epiploic appendages [1] occurring due to ischemic infarction as a result of appendage torsion or spontaneous thrombosis [2]. Usually, it affects patients from second to fifth decades,

H. Matos $(\bowtie) \cdot$ I. Costa

Department of Radiology, Centro Hospitalar Médio Tejo, EPE,

Torres Novas, Portugal

e-mail: hugocmatos@gmail.com being more common in women and obese patients [2,3]. The most common site of presentation is the sigmoid colon $[2,3]$. In secondary epiploic appendagitis, the process is due to other inflammatory process such as diverticulitis, appendicitis, or pancreatitis [2].

Clinically, patients present with abdominal pain and localized tenderness. Differential diagnosis depends on site of presentation, being considered diverticulitis, omental infarction, mesenteric panniculitis, acute appendicitis if right-sided, and omental neoplasms [2].

The imaging findings represent the epiploic appendage as an ovoid hyperechoic pericolic lesion at ultrasound (Fig. 1)

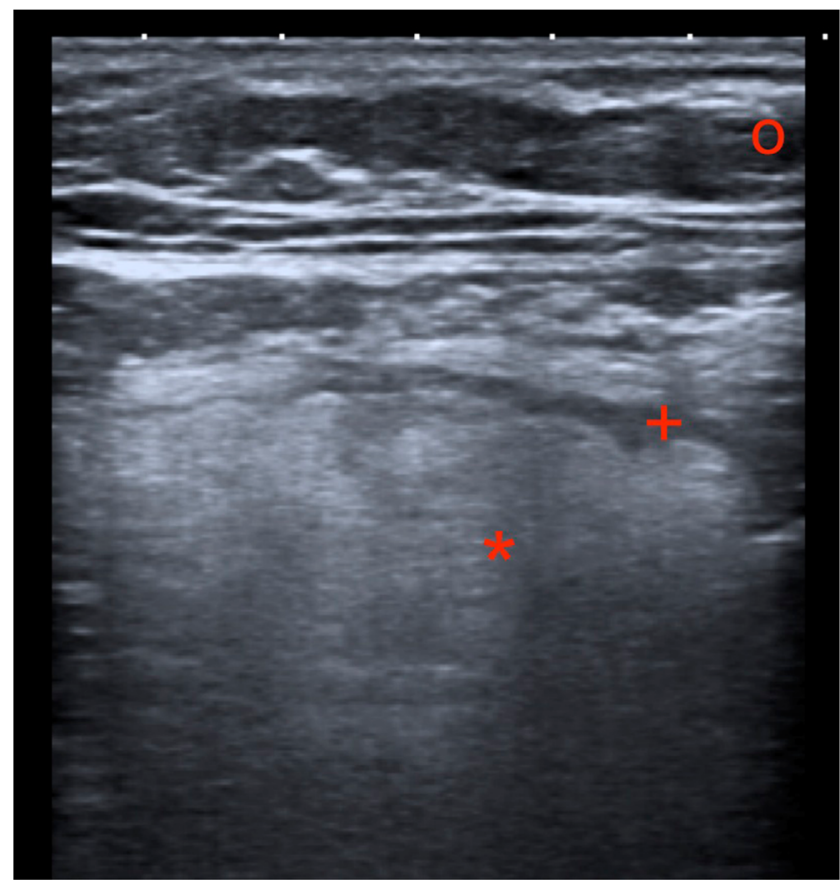

Fig. 1 Ultrasound examination with linear (high resolution) transducer. Beneath the superficial tissue (circle), there was an ovoid hyperechoic lesion (asterisk) with and hypoechoic halo (plus sign) 


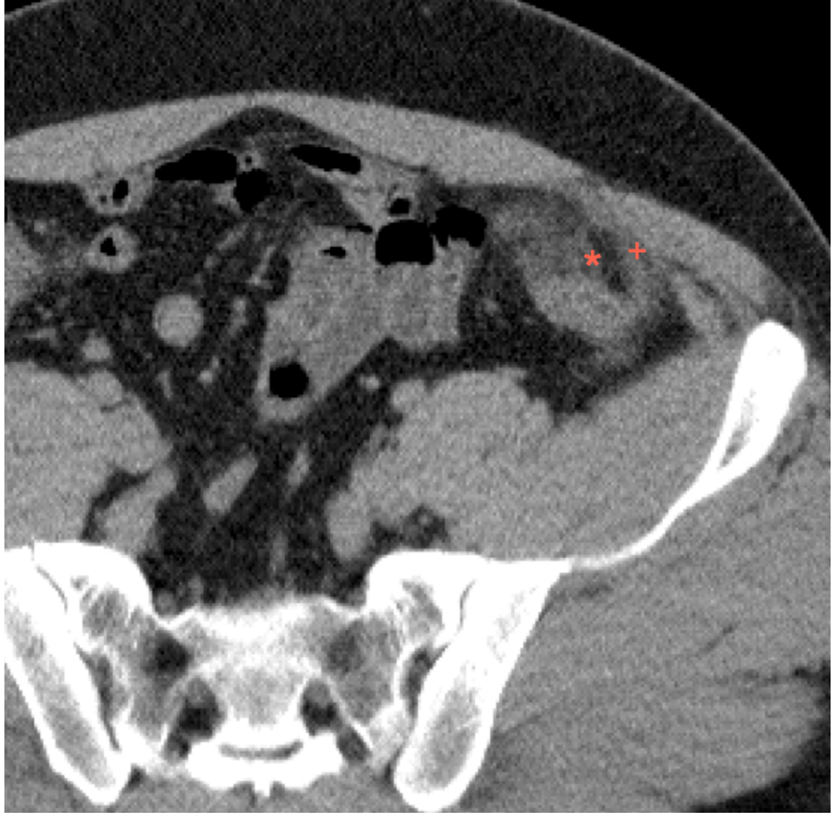

Fig. 2 CT examination. Beneath the superficial tissue, there was an ovoid hypodense lesion (asterisk) with and hyperdense halo (plus sign)

and hypodense at $\mathrm{CT}$ (Fig. 2) due to the fat composition, with an hypoechoic halo at ultrasound (Fig. 1) and hyperdense at
CT (Fig. 2), representing the inflamed visceral peritoneal covering of the appendage [2] with paracolonic inflammatory changes.

Epiploic appendagitis is a self-limiting entity with clinical features similar to other inflammatory abdominal processes [1-4]. The referring surgeon should have high index of suspicion about this entity, pointing out the area of tenderness, and the radiologist should also be aware of this condition since its correct identification on imaging examinations could prevent unnecessary surgery.

\section{References}

1. Rioux M, Langis P (1994) Primary epiploic appendagitis: clinical, US and CT findings in 14 cases. Radiology 191:523-526

2. Almeida AT, Melão L, Viamonte B et al (2009) Epiploic appendagitis: an entity frequently unknown to clinicians - diagnostic imaging, pitfalls and look-alikes. AJR 193:1243-1251

3. Sand M, Gelos M, Bechara F et al (2007) Epiploic appendagitis: clinical characteristics of an uncommon surgical diagnosis. BMC Surg 1:7-11

4. Singh AK, Gervais DA, Hahn PF et al (2005) Acute epiploic appendagitis and its mimics. Radiographics 25:1521-1534 